\title{
Five-year record of atmospheric precipitation chemistry in urban Beijing, China
}

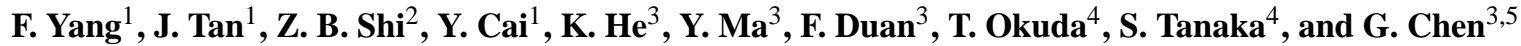 \\ ${ }^{1}$ Key Laboratory of Computational Geodynamics, College of Earth Science, Graduate University of Chinese Academy of \\ Sciences, Beijing 100049, China \\ ${ }^{2}$ School of Geography, Earth and Environmental Science, University of Birmingham, Edgbaston Birmingham B15 2TT, UK \\ ${ }^{3}$ School of Environment, Tsinghua University, Beijing100084, China \\ ${ }^{4}$ Department of Applied Chemistry, Faculty of Science and Technology, Keio University, 3-14-1 Hiyoshi, Kohoku-ku, \\ Yokohama 223-8522, Japan \\ ${ }^{5}$ Chongqing Environmental Protection Bureau, Chongqing 401147, China
}

Correspondence to: K. He (hekb@tsinghua.edu.cn)

Received: 8 September 2011 - Published in Atmos. Chem. Phys. Discuss.: 19 October 2011

Revised: 1 February 2012 - Accepted: 13 February 2012 - Published: 21 February 2012

\begin{abstract}
To investigate the chemical characteristics of precipitation in the polluted urban atmosphere in Beijing and possible mechanisms influencing their variations, a total of 131 event-based precipitation samples were collected from March 2001 to August 2005. The concentrations of major ions in the samples were analyzed by using ion chromatography. Intermediate $\mathrm{pH}(6.1-7.3)$ was recorded in approximately two-thirds of the precipitation samples and acidic $\mathrm{pH}(4.2-5.6)$ in only $16 \%$ of the samples. However, the precipitation acidity was on the growth track and the process was likely being accelerated. $\mathrm{SO}_{4}^{2-}, \mathrm{NO}_{3}^{-}, \mathrm{NH}_{4}^{+}$, and $\mathrm{Ca}^{2+}$ were the most abundant ions in the precipitations, with their single volume-weighted mean (VWM) concentration all above $100 \mu \mathrm{eq} 1^{-1}$. The two major anions and two major cations accounted for more than $80 \%$ of total anionic and cationic mass, respectively. The VWM SO $\mathrm{V}_{4}^{2-}$ concentration decreased by $13 \%$ compared to that during $1995-$ 1998 , much less than the $58 \%$ reduction in the annual average $\mathrm{SO}_{2}$ concentration from 1998 to 2005 in Beijing. What seems more counterintuitive is that the $\mathrm{VWM} \mathrm{NO}_{3}^{-}$concentration nearly doubled over the period although the annual average $\mathrm{NO}_{2}$ concentration decreased by $5 \%$ from 1998 to 2005. These results imply that the conversion of gaseous precursors to acid compounds and/or the regional transport were reinforced over the decade. The average ratio of neutralizing potential to acidifying potential (i.e. NP/AP) was as high as 1.2 but experienced an evident decline trend. This was mainly ascribed to reduced input of $\mathrm{NH}_{4}^{+}$and $\mathrm{Ca}^{2+}$ and
\end{abstract}

increased input of $\mathrm{NO}_{3}^{-}$. Furthermore, the equivalent mass ratio of $\mathrm{NO}_{3}^{-}$to non-sea-salt $\mathrm{SO}_{4}^{2-}$ presented an increasing trend over the study period, suggesting that the contribution of $\mathrm{NO}_{3}^{-}$to the precipitation acidity increased in recent years. However, the mean ratio was only $0.37 \pm 0.11$ in the study period, which is significantly lower than those reported in some metropolitan areas in developed countries. This shows that the precipitation acidity in Beijing was still dominantly from $\mathrm{SO}_{2}$ while the $\mathrm{SO}_{2}$ contribution was progressively substituted by $\mathrm{NO}_{\mathrm{x}}$.

\section{Introduction}

Long-term variation in the chemical characteristics of dry and wet depositions provides important information on the temporal evolution of atmospheric pollution, and can be used as a pertinent indicator to evaluate natural process versus anthropogenic influences (Grodzińska-Jurczak and Godzik, 1999; Tang et al., 2005). Because wet deposition often plays a more important role in flux compared to dry deposition, chemical analyses of precipitation enables a partial assessment of local air quality (Özsoy et al., 2008). In China, acid deposition has been one of the most significant environmental issues since the late 1970s. Widespread acid rain was observed in southern and southwestern China before the 1990s (Zhao et al., 1988; Wang and Wang, 1995; Ding et al., 1997), and more recently it has extended to eastern and 


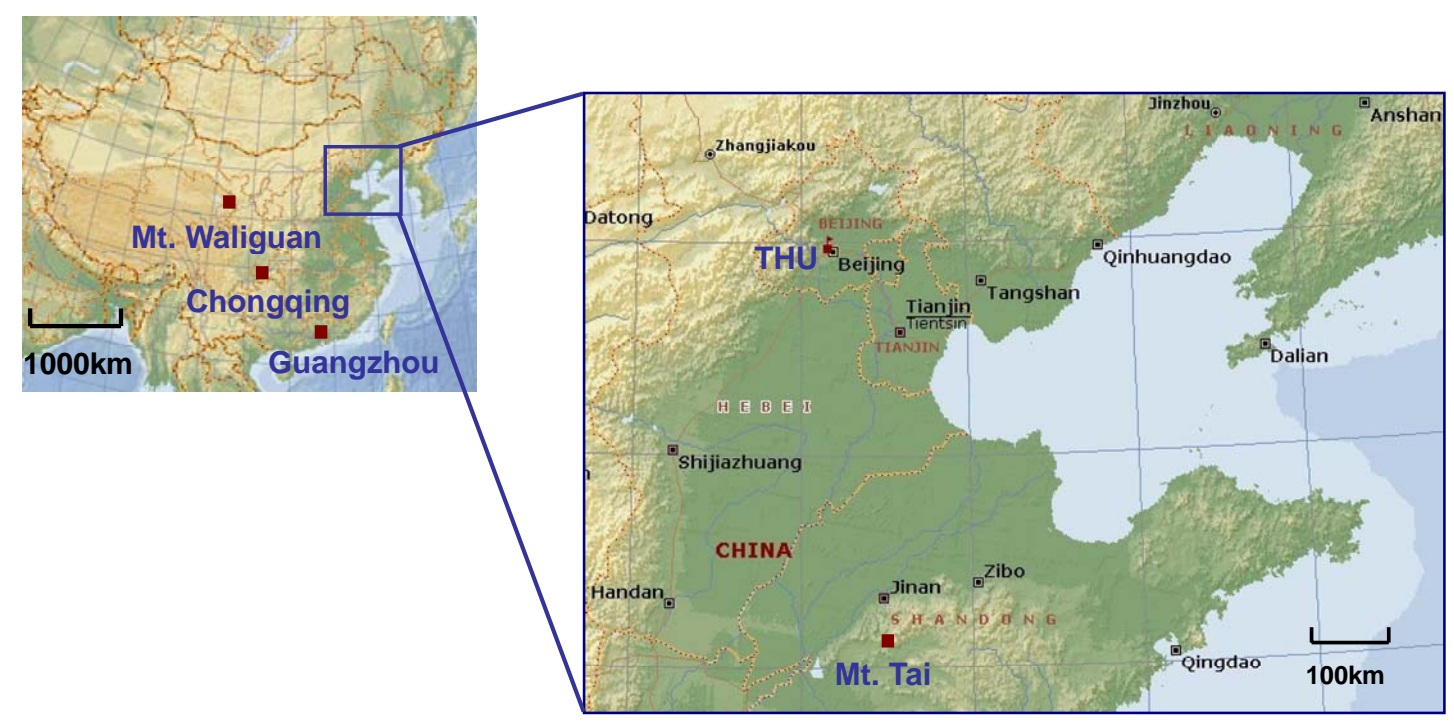

Fig. 1. Sampling site (THU) in Beijing. The locations of some major cities with more than one million population related in this study (such as Tianjin, Shijiazhuang, Jinan, Handan, and Zibo) are marked with square symbol in the right-hand figure. The locations of remote Mt. Waliguan $\left(36^{\circ} 17^{\prime} \mathrm{N}, 100^{\circ} 54^{\prime} \mathrm{E}\right.$; elevation $\left.3816 \mathrm{~m}\right)$ with rare anthropogenic impact, Mt. Tai, and two typical mega cities suffering severe acid rain - Chongqing and Guangzhou - are also marked in the left-hand figure. The topographical map was derived from the Microsoft ${ }^{\circledR}$ Encarta ${ }^{\circledR} 2009$ @ 1993-2008.

central China (Larssen et al., 2006; Huang et al., 2008; Wang and Xu, 2009; Xie et al., 2009; Tang et al., 2010; Ge et al., 2011). Beijing is located out of the traditional regions impacted by acid rain in China. However, high concentrations of air pollutants in and around Beijing most likely lead to high loadings of various chemical species to the ecosystem through atmospheric depositions. For example, the average concentrations of sulfate and nitrate in fine particles - two dominant acidic species - were much higher than those in some cities suffering severe acid deposition in southern China, such as Chongqing and Guangzhou (Yang et al., 2011b). Thus the trend in precipitation chemistry and its influence on the ecosystem are of great concern, particularly when considering the fast economic and population growth in Beijing.

As the capital and one of the most populated mega cities in China, Beijing has experienced rapid urbanization and motorization in the past three decades, which leads to soaring demand for energy. During the process, the motor vehicle pollution emerges and becomes increasingly prominent while the traditional pollution caused by coal burning has not yet been effectively controlled, a common phenomenon in Chinese megacities (He et al., 2011). In addition, a great deal of construction activities inevitably cause fugitive dust and exacerbate particulate pollution. To improve the capital's air quality, the municipal government has initiated a series of clean air programs starting in 1998 (www.bjepb.gov.cn), and Beijing has been leading the country in progressive introduction of increasingly stringent emission standards for motor vehicles and coal-fired boilers compared to state criteria. As a result, the air quality compliance days have kept increasing thereafter (www.bjepb.gov.cn), but less than what is expected in terms of particulate pollution as compared to $\mathrm{SO}_{2}$ and $\mathrm{NO}_{2}$ (Yang et al., 2011a).

Meanwhile, the precipitation acidification in Beijing is undergoing an evident increasing trend, especially under the background of complex air pollution mentioned above (Ding et al., 1997; Wang and Zhang, 1997; Feng et al., 2001; Hu et al., 2005). Some recent studies showed that $\mathrm{pH}$ and precipitation chemistry in Beijing were noticeably different before and after the year of 2000, which was likely related to the variations in atmospheric pollution type (Tang et al., 2005; Hu et al., 2005; Xu and Han, 2009). To our knowledge, there are no studies that are based on long-term surface measurements to track the changing precipitation chemistry along with the changing emissions of acidic precursors and neutralizing substances in Beijing after 2000. In 2001, we initiated a precipitation monitoring program in urban Beijing to evaluate the magnitude as well as temporal trends and sources of acids and toxics substances in atmospheric depositions. This paper will summarize the major findings with a focus on the temporal variations in the precipitation chemistry. Possible mechanisms influencing these variations will also be discussed. 


\section{Experimental}

\subsection{Sampling location and sample collection}

Beijing is located at the northern tip of the Great North China Plain with a landmass of $16410 \mathrm{~km}^{2}$ (Fig. 1). As one of the most populated cities in China, its 20 million inhabitants are concentrated in the urbanized area, which is only $6 \%$ of the city's landmass (Beijing Municipal Bureau of Statistics, 2011). The main terrain of Beijing is plain, with surrounding mountains on three sides, i.e. the Mongolia to the north, the Yanshan Mountain to the northeast. The Bohai Sea is about $160 \mathrm{~km}$ to the southeast. This topography does not favor the dispersion of the air pollutants. Lying in the north warm temperate zone, Beijing has typical continental monsoon climate with four distinct seasons. From November-April (dry months), the prevailing airflow from the northwest is dry and cold, while at other times the local winds are moderate and mostly from the south and southeast (Yang et al., 2011a).

Sampling of atmospheric precipitations was conducted in the semi-residential area inside the campus of TsingHua University (here referred to as THU, $40^{\circ} 19^{\prime} \mathrm{N}, 116^{\circ} 19^{\prime} \mathrm{E}$ ) from 15 March 2001 to 18 August 2005 (Fig. 1). About $12 \mathrm{~km}$ northwest of the city centre, the THU site lies within the western part between the northern fourth and fifth ring roads, which are two of the artery roads with busy traffic encircling urban area at about 9 and $14 \mathrm{~km}$ radii from the city centre, respectively. Precipitations were collected with a dry-wet deposition auto-sampler (DRS-154W, Koshin Denki Kogyo, Japan), which was deployed on the rooftop of a $5 \mathrm{~m}$ tall building. The sampler has a removable lid activated by a wetness sensor, which opens the funnel above a 51 polyethylene bucket under a funnel of $155 \mathrm{~mm}$ in diameter when precipitation happens. The wet deposition sample was collected for every continuous rainfall. In total, 137 precipitation samples were collected over the study period.

\subsection{Sample analysis and quality control}

The precipitation samples were weighed in the laboratory and calculated for the volume. The precipitations were then filtered through a Millipore filter with a pore size of $0.45 \mu \mathrm{m}$. The $\mathrm{pH}$ of the filtrate was measured with a $\mathrm{pH}$ meter $(\mathrm{pH} / \mathrm{Ion}$ meter F-24, Horiba) under controlled room temperature $\left(25^{\circ} \mathrm{C}\right)$, and the electrical conductivity (EC) was measured with an electrical conductivity meter (AOL-40, Denki Kagaku Keiki). $\mathrm{H}^{+}$concentration was calculated from the $\mathrm{pH}$ of the filtrate. The concentrations of ten major ions $\left(\mathrm{Na}^{+}, \mathrm{NH}_{4}^{+}\right.$, $\mathrm{K}^{+}, \mathrm{Ca}^{2+}, \mathrm{Mg}^{2+}, \mathrm{F}^{-}, \mathrm{Cl}^{-}, \mathrm{NO}_{3}^{-}, \mathrm{SO}_{4}^{2-}$, and $\mathrm{HCO}_{3}^{-}$) were determined with Ion Chromatography (IC7000-1, Yokokawa Analytical Systems) (Okuda et al., 2005). The separator column was ICS-C25 (YAN) and the eluent was $5 \mathrm{mM}$ Tartaric acid/1 $\mathrm{mM}$ 2,6-Pyridinedicarboxylic acid/24 mM Boric acid $1.0\left[\mathrm{ml} \mathrm{min}^{-1}\right]$ for cations. For anions except $\mathrm{HCO}_{3}^{-}$ the separator column was AS12A (Dionex) and the eluent was $2 \mathrm{mM} \mathrm{Na}_{2} \mathrm{CO}_{3} / 4 \mathrm{mM} \mathrm{NaHCO}{ }_{3} 1.0\left[\mathrm{ml} \mathrm{min}^{-1}\right]$, while for $\mathrm{HCO}_{3}^{-}$they were ICE-AS1 (Dionex) and Milli-Q (Millipore), respectively. Note that we excluded 6 out of the 137 precipitation samples, whose volume is too small to reliably determine the concentrations of all the above mentioned ions except $\mathrm{HCO}_{3}^{-}$.

Precision of ionic analysis was determined from at least 4 replicate measurements. The result showed that the variation for $\mathrm{Na}^{+}, \mathrm{NH}_{4}^{+}, \mathrm{Ca}^{2+}, \mathrm{Mg}^{2+}, \mathrm{Cl}^{-}, \mathrm{NO}_{3}^{-}, \mathrm{SO}_{4}^{2-}$, and $\mathrm{HCO}_{3}^{-}$ was $\leq 2 \%$, while for $\mathrm{K}^{+}$it was $7 \%$. The quality of analytical data was also checked by a cation-anion balance and by comparison of the measured conductivity with the conductivity calculated from the concentration of all measured ions and their specific conductivity. As shown in Fig. 2a, the conductivity ratio of that calculated to measured was $>1$, indicative of an ionic deficiency in these cases. The ion balance check proved to be reliable according to the acceptable range $(15-30 \%)$ set for samples having ion sum $>100 \mu \mathrm{eq} \mathrm{l}^{-1}$ by USEPA (Ayers, 1995). The ratio of total anions to cations was systematically $<1$ (Fig. 2b), suggesting an anion deficit. This predominance is frequently reported in the literature, and usually ascribed to some unmeasured anions such as bicarbonate (if not included) and short-chain organic acids (Zhang et al., 1996; Hontoria et al., 2003).

\section{Results and discussion}

\subsection{Precipitation amount and $\mathrm{pH}$ distribution}

The annual total precipitation amount was $345,461,411$, and $546 \mathrm{~mm}$ from 2001 to 2004 with an average of $441 \mathrm{~mm}$ for the four years. These volumes were similar to the reported range of 339-483 $\mathrm{mm}$ for the whole city through the years (www.bjstats.gov.cn) but largely lower than long-term average of $630 \mathrm{~mm}$ in Beijing Metropolis (www.bjclimate.com). As shown in Fig. 3, monthly mean precipitation amount varied markedly with a peak in the summer. About $78 \%$ of the rain was deposited from June to September (rainy months). The volume-weighted mean (VWM) EC in the precipitation was $66.5 \mu \mathrm{S} \mathrm{cm}^{-1}$, which was larger by a factor of 4.6 than that $\left(14.6 \mu \mathrm{S} \mathrm{cm}^{-1}\right)$ measured at a remote site in Mt. Waliguan (Fig. 1), which is the Global Atmosphere Watch Baseline Observatory of World Meteorological Organization (WMO) located at the eastern tip of Qinghai-Tibetan plateau in Northwest China (Tang et al., 2000). This indicates a substantial impact of anthropogenic pollution on the urban atmospheric environment in Beijing.

As illustrated in Fig. 4a, the frequency distribution of precipitation $\mathrm{pH}$ is similar to a unimodal distribution. This is very different from the bimodal $\mathrm{pH}$ distribution found in the Mediterranean precipitation (Aiuppa et al., 2003). The $\mathrm{pH}$ value of single precipitation varied from 4.2 to 7.5 with an arithmetic mean of 6.3 and the VWM of 6.0 for the total 131 precipitation samples. Intermediate $\mathrm{pH}(6.1-7.5)$ was 
(a)

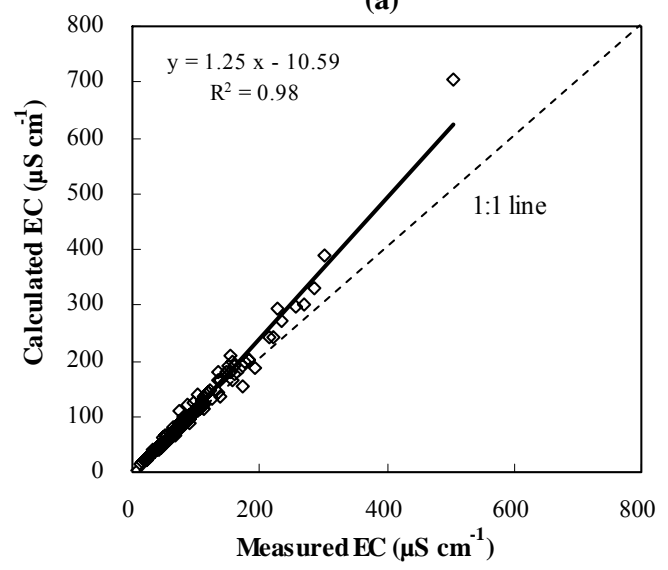

(b)

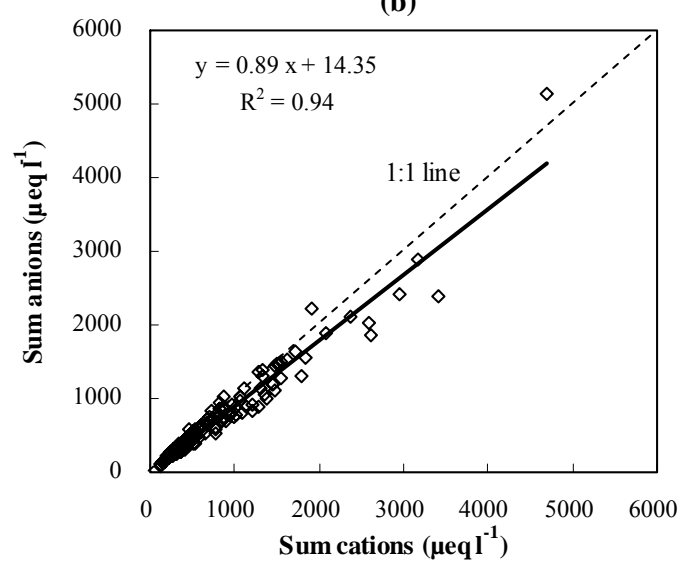

Fig. 2. Quality control of chemical analysis: (a) the calculated EC versus the measured EC and (b) the ionic balance, $n=131$.

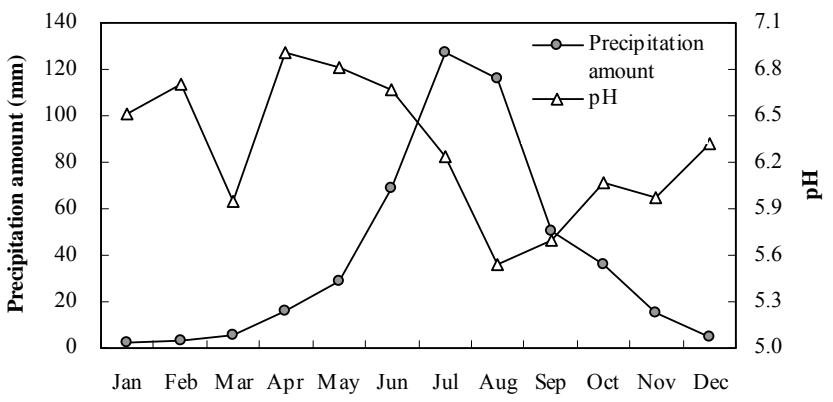

Fig. 3. Monthly average amount and VWM pH values of the precipitations.

recorded in approximately two-thirds of precipitation samples, while acidic $\mathrm{pH}(\mathrm{pH}<5.6)$ was observed in only $16 \%$ of the samples. This distribution reflected the alkaline nature of rainwater in Beijing. It should be noted, however, that there existed a decreasing trend in the rainfall $\mathrm{pH}$ based on linear regression (Fig. 4b), which is consistent with the trend during 1980-2000 as noted earlier (Ding et al., 1997; Wang and Zhang, 1997). Furthermore, nine of thirteen low $\mathrm{pH}$ $(<5.0)$ rain samples and the three lowest $\mathrm{pH}(<4.5)$ rain samples were collected in the latter two years (Fig. 4b). Therefore, the buffering capacity of Beijing precipitation was decreasing and the process was likely being accelerated, pointing to increased input of acid compounds and/or reduced input of neutralization of base agents. This will be further discussed in Sect. 3.4. The monthly VWM pH values varied from 5.3 to 6.8 with an average of 6.2. Only August had a VWM pH less than 5.6. There were eleven low $\mathrm{pH}$ rains collected during July-September and the majority of them were in August. Since summertime rainfall volume shared about two-thirds of annual volumes and usually presented low $\mathrm{pH}$ values (Fig. 3), the yearly wet deposition acidity was mainly determined by the rains falling in this season.

\subsection{Chemical composition and sources of major ions}

Figure 5 illustrates the statistics of concentrations of ions in the precipitations, including the 10th, 25th, 75th, and 90th percentiles and $\mathrm{VWM}$ of each ion. $\mathrm{SO}_{4}^{2-}, \mathrm{NO}_{3}^{-}, \mathrm{NH}_{4}^{+}$, and $\mathrm{Ca}^{2+}$ were the most abundant ions as their single VWM concentration was all above $100 \mu \mathrm{eq} 1^{-1}$. $\mathrm{NH}_{4}^{+}$plus $\mathrm{Ca}^{2+}$ summed to $502 \mu \mathrm{eq} \mathrm{I}^{-1}$ and comprised $83 \%$ of total cationic mass while $\mathrm{SO}_{4}^{2-}$ plus $\mathrm{NO}_{3}^{-}$accounted for $84 \%$ of total anionic mass. $\mathrm{SO}_{4}^{2-}$ was the most abundant single ionic component in the precipitations, accounting for $30 \%$ of total ionic mass. $\mathrm{NO}_{3}^{-}$was the second most abundant anion, followed in decreasing order by $\mathrm{HCO}_{3}^{-}, \mathrm{Cl}^{-}$and $\mathrm{F}^{-}$. For the cations, $\mathrm{NH}_{4}^{+}$and $\mathrm{Ca}^{2+}$ were followed in decreasing concentration by $\mathrm{Mg}^{+}, \mathrm{Na}^{+}$, and $\mathrm{K}^{+}$.

The major anthropogenic ions $-\mathrm{SO}_{4}^{2-}, \mathrm{NO}_{3}^{-}$and $\mathrm{NH}_{4}^{+-}$ accounted for $63 \%$ of the total ionic mass, indicating that anthropogenic sources predominated in rainfall ions. Despite high contribution of anthropogenic anions such as $\mathrm{SO}_{4}^{2-}$ and $\mathrm{NO}_{3}^{-}, \mathrm{H}^{+}$accounted for only $0.2 \%$ of total inorganic ionic mass due to the extensive neutralization by alkaline substances. Two major crustal-related ions $-\mathrm{Ca}^{2+}$ and $\mathrm{Mg}^{2+}$ - contributed $28 \%$ to the total ionic mass, indicating crustal material was an important contributor to precipitation neutralization. The non-sea-salt calcium (nss- $\mathrm{Ca}^{2+}$, calculated from the ion ratio $\mathrm{Ca}^{2+} / \mathrm{Na}^{+}$in seawater equal to 0.0379) accounted for $99.6 \%$ of the total calcium (i.e. non-sea-salt plus sea-salt calcium) for all the precipitation samples, indicating that sea salt did not have strong impact on wet deposition in Beijing. The non-sea-salt sulfate (nss- $\mathrm{SO}_{4}^{2-}$, calculated from the ion ratio $\mathrm{SO}_{4}^{2-} / \mathrm{Na}^{+}$in seawater equal to 0.252 ) accounted for $97.8 \%$ of the total sulfate.

Table 1 lists the VWM pH and VWM concentrations of each ion, in addition to those from other earlier studies conducted in Beijing and other selected locations in East Asia. Compared to the long-term observation from 1990 to 2002 
(a)

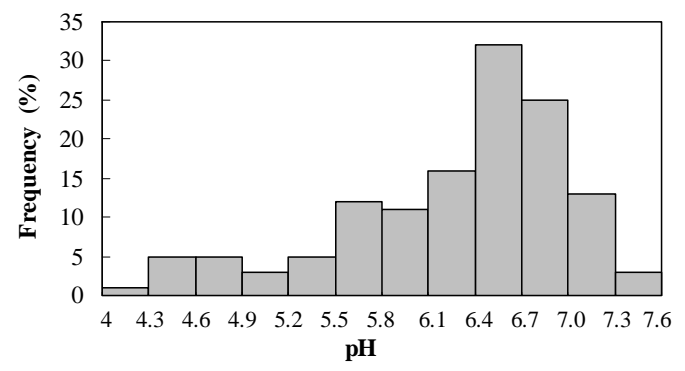

(b)

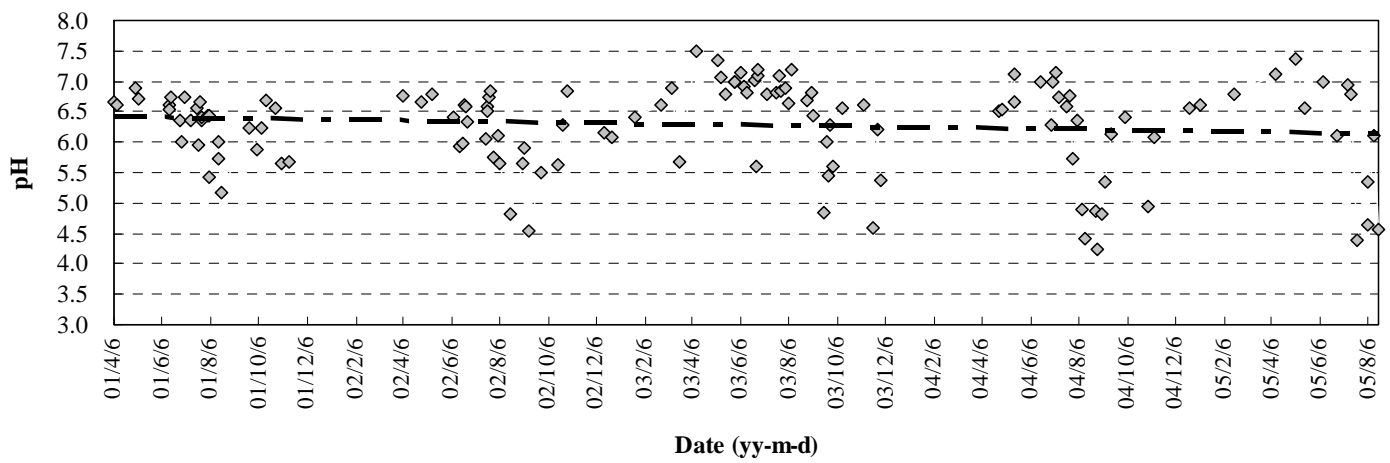

Fig. 4. Frequency distribution (a) and time series (b) of precipitation $\mathrm{pH}$ values, $n=131$.

Table 1. The VWM pH and VWM concentrations $\left(\mu \mathrm{eq} 1^{-1}\right)$ of ions in precipitations in this study and some selected location in East Asia ${ }^{\mathrm{a}}$.

\begin{tabular}{lcccccccccccc}
\hline Cities & Period & $\mathrm{pH}$ & $\mathrm{Na}^{+}$ & $\mathrm{NH}_{4}^{+}$ & $\mathrm{K}^{+}$ & $\mathrm{Ca}^{2+}$ & $\mathrm{Mg}^{2+}$ & $\mathrm{F}^{-}$ & $\mathrm{Cl}^{-}$ & $\mathrm{NO}_{3}^{-}$ & $\mathrm{SO}_{4}^{2-}$ & $\mathrm{References}^{2}$ \\
\hline Beijing & $2001-2005$ & 6.0 & 22.5 & 236 & 13.8 & 209 & 48.4 & 15.4 & 34.9 & 106 & 314 & This study \\
Beijing & $1995-1998$ & 6.9 & 57.2 & 135 & 33.3 & 464 & 86.0 & 26.9 & 97.2 & 54.5 & 359 & Feng et al. (2001) \\
Guangzhou & $2005-2006$ & 4.5 & 18.0 & 66.2 & 9.0 & 131 & 9.0 & 12.0 & 21.0 & 51.8 & 202 & Huang et al. (2009) \\
Mt. Tai & $2004-2006$ & 4.7 & 25.3 & 82.2 & 7.7 & 61.4 & 6.2 & $-\mathrm{b}$ & 15.5 & 30.2 & $132^{\mathrm{c}}$ & Wang et al. (2008) \\
Waliguan & 1997 & 6.4 & 8.7 & 45.5 & 3.8 & 34.0 & 12.1 & - & 6.1 & 8.3 & 24.0 & Tang et al. (2000) \\
Tokyo Metropolitan & $1990-2002$ & 4.5 & 37.0 & 40.4 & 2.9 & 24.9 & 11.5 & - & 55.2 & 30.5 & 50.2 & Okuda et al. (2005) \\
\hline
\end{tabular}

a The selected locations in China are marked in Fig. 1. ${ }^{\mathrm{b}}$ Not determined. ${ }^{\mathrm{c}} \mathrm{Nss}-\mathrm{SO}_{4}^{2-}$.

in the Tokyo Metropolitan area suffering severe acid rain, the VWM concentrations of $\mathrm{SO}_{4}^{2-}$ and $\mathrm{NO}_{3}^{-}$in Beijing were higher by a factor of 3.8 and 7.6, and those of $\mathrm{NH}_{4}^{+}$and $\mathrm{Ca}^{2+}$ by a factor of 6.5 and 9.6 , respectively. The $\mathrm{SO}_{4}^{2-}$ level was also considerably higher than those measured in some typical acid rain regions in China, such as Guangzhou (Fig. 1, Table 1) (Huang et al., 2009). In comparison with those monitored at the remote Mt. Waliguan site, the VWM concentrations of $\mathrm{SO}_{4}^{2-}$ and $\mathrm{Ca}^{2+}$ in Beijing precipitations were 7.7 and 7.0 times higher, respectively. These comparisons reveal that both crustal-related and anthropogenic sources (such as fossil fuel combustion) had significant impact on the ambient environment in urban Beijing.

Factor analysis was performed to further investigate the major sources of chemical species in the precipitations.
Three factors were identified with the cumulative variance more than $90 \%$ (Table 2). The communalities of all the ions are no less than 0.80 , indicating that these extracted factors are reasonable. The first factor, which explains $40 \%$ of variance, is strongly correlated with $\mathrm{Cl}^{-}, \mathrm{Na}^{+}$, and $\mathrm{Mg}^{2+}$, and moderately correlated with $\mathrm{K}^{+}, \mathrm{F}^{-}$, and $\mathrm{NO}_{3}^{-}$. This factor was likely associated with certain anthropogenic sources, such as industrial emissions, municipal waste incineration, biomass burning, coal combustion, and fugitive dust as well. It is noted that the concentration of $\mathrm{F}^{-}$was one to two orders of magnitude higher than those observed in Tokyo (1.7-1.9 $\mu \mathrm{eq}^{-1}$ ) in Japan (Feng et al., 2003), Virginia $\left(0.6 \mu \mathrm{eq} 1^{-1}\right)$ and Delaware $\left(0.3 \mu \mathrm{eq} \mathrm{I}^{-1}\right)$ in USA (Barnard and Nordstrom, 1982), Mid-Wales $\left(0.3 \mu \mathrm{eq} 1^{-1}\right)$ in the UK (Neal, 1989), and much higher than the World average 


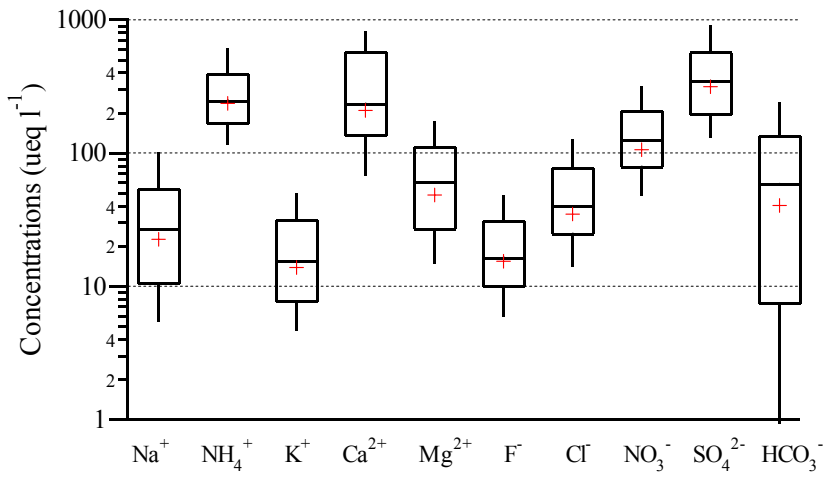

Fig. 5. Statistics of concentrations of ions in the precipitations. The box plots indicate the 10th, 25th, 75th, and 90th percentiles and VWM (cross symbol) of each ion.

(5.3 $\left.\mu \mathrm{eq} \mathrm{1}^{-1}\right)$ (Zheng, 1996), implying that a large fraction of the $\mathrm{F}^{-}$in Beijing precipitation was likely from anthropogenic sources. Based on a field study during 1995-1998, Feng et al. (2003) ascribed the soil dust and coal combustion as the two major sources of $\mathrm{F}^{-}$in Beijing precipitation. Although a strong correlation exists between $\mathrm{Na}^{+}$and $\mathrm{Cl}^{-}$ $(r=0.89)$, the association of $\mathrm{Na}$ and $\mathrm{Cl}$ with the influence of sea breeze could be only a minor source, consistent with the findings by Tang et al. (2005) and Xu and Han (2009). This is supported by the fact that the average $\mathrm{Na}^{+}$and $\mathrm{Cl}^{-}$ratio of 2.1 (ranging from 0.7 to 13) was much higher than the reported ratio of 1.16 from seawater (Moller, 1990). This is understandable since Beijing is about $160 \mathrm{~km}$ away from the Bohai Sea in the southeast and the wind from that direction in summer is usually mild (Yang et al., 2011a).

Factor 2 has high loading for $\mathrm{SO}_{4}^{2-}, \mathrm{NO}_{3}^{-}$, and $\mathrm{NH}_{4}^{+}$, suggestive of the secondary pollution formed in the atmosphere from their precursors $-\mathrm{SO}_{2}, \mathrm{NO}_{\mathrm{x}}$, and $\mathrm{NH}_{3}$. While $\mathrm{SO}_{2}$ and $\mathrm{NO}_{\mathrm{x}}$ are believed to be mainly emitted from fossil fuel combustion such as coal combustion and vehicle tailpipe emission, the major anthropogenic emissions of ammonia in East Asia were estimated to be mainly from chemical fertilizer used in agriculture, livestock breeding, and energy consumption (Zhao and Wang, 1994; Fujita et al., 2000). Vehicle emission, chemical engineering, biologic process and biomass burning could play a role as well in the high levels of $\mathrm{NH}_{4}^{+}$in Beijing precipitation (Tang et al., 2000; Hu et al., 2005).

Factor 3 is dominated by $\mathrm{Ca}^{2+}, \mathrm{F}^{-}, \mathrm{NO}_{3}^{-}$, and $\mathrm{K}^{+}$, likely indicative of soil dust as a major source. It is noted that there are plenty of calcareous soil and high aerosol loadings in Beijing and surrounding region, of which a large portion was expected from soil dust (Yang et al., 2004; Guinot et al., 2007). Also noted is that a significant part of $\mathrm{NO}_{3}^{-}$is usually associated with soil particles in coarse mode (Seinfeld and Pandis, 2006).
Table 2. Factor analysis of ions in precipitation.

\begin{tabular}{lcccc}
\hline Variable & Factor 1 & Factor 2 & Factor 3 & Communality \\
\hline $\mathrm{Cl}^{-}$ & 0.89 & 0.17 & 0.31 & 0.92 \\
$\mathrm{Na}^{+}$ & 0.88 & 0.31 & 0.28 & 0.94 \\
$\mathrm{Mg}^{2+}$ & 0.82 & 0.36 & 0.33 & 0.91 \\
$\mathrm{~K}^{+}$ & 0.65 & 0.36 & 0.54 & 0.84 \\
$\mathrm{NH}^{+}$ & 0.20 & 0.93 & 0.23 & 0.96 \\
$\mathrm{SO}_{4}^{2-}$ & 0.43 & 0.75 & 0.43 & 0.93 \\
$\mathrm{NO}_{3}^{-}$ & 0.50 & 0.60 & 0.54 & 0.90 \\
$\mathrm{Ca}^{2+}$ & 0.38 & 0.36 & 0.82 & 0.95 \\
$\mathrm{~F}^{-}$ & 0.56 & 0.40 & 0.58 & 0.80 \\
Variance (\%) & 39.9 & 27.3 & 23.4 & \\
\hline
\end{tabular}

\subsection{Temporal variations in the concentrations of major ions}

Monthly average concentrations of each ion in the precipitations were subject to large variations (Fig. 6). Both higher loadings of crustal-related and anthropogenic ions usually appeared during the dry months from November to April while lower loadings in rainy months. This seasonal pattern was most likely due to the combined effect of seasonal variations in emission and rain intensity. During the dry months, the northwesterly Asian monsoon was dominant, leading to frequent uplift of wind-blown mineral particles from both local areas and remote deserts or arid regions. In addition, the coal combustion activities were highly enhanced (about 5 million tons additional coal consumed) for heating in Beijing during the official four-month heating period lasting from mid-November to mid-March, resulting in extra anthropogenic emissions of gaseous pollutants and particles (He et al., 2001). Meanwhile, usually there are sparse rains (about $19 \%$ of the annual rainwater volume in this study) during this period. For the effect of rain intensity on ionic mass, many previous studies demonstrated in different areas that ionic concentrations decreased with increasing precipitation amount due to processes such as diffusion aerosol, initial rain evaporation and dilution (Tuncer et al., 2001; Feng et al., 2001; Xie et al., 2009). The monthly variations in the VWM concentrations of precipitation ions in the present study were largely controlled by rainwater amount as well since all the ions were more or less negatively correlated with precipitation volume (correlation coefficient $r=-0.18$ to -0.34 ).

All ionic species reached their maximum monthly average concentrations in March 2003, followed by the preceding month. It is noted that there were only two precipitation samples collected in March over the study period and both in 2003. Of the two samples the one with much higher volume $(17.4 \mathrm{~mm}$ vs. $5.1 \mathrm{~mm}$ for the other event) was collected on 20 March when daily $\mathrm{PM}_{10}$ concentration was as high as $179 \mu \mathrm{g} \mathrm{m}^{-3}$. In addition, the average ionic concentrations in July and August of 2003 were higher than those in other years by a factor of 2.6-3.4. It is worth noting that the 


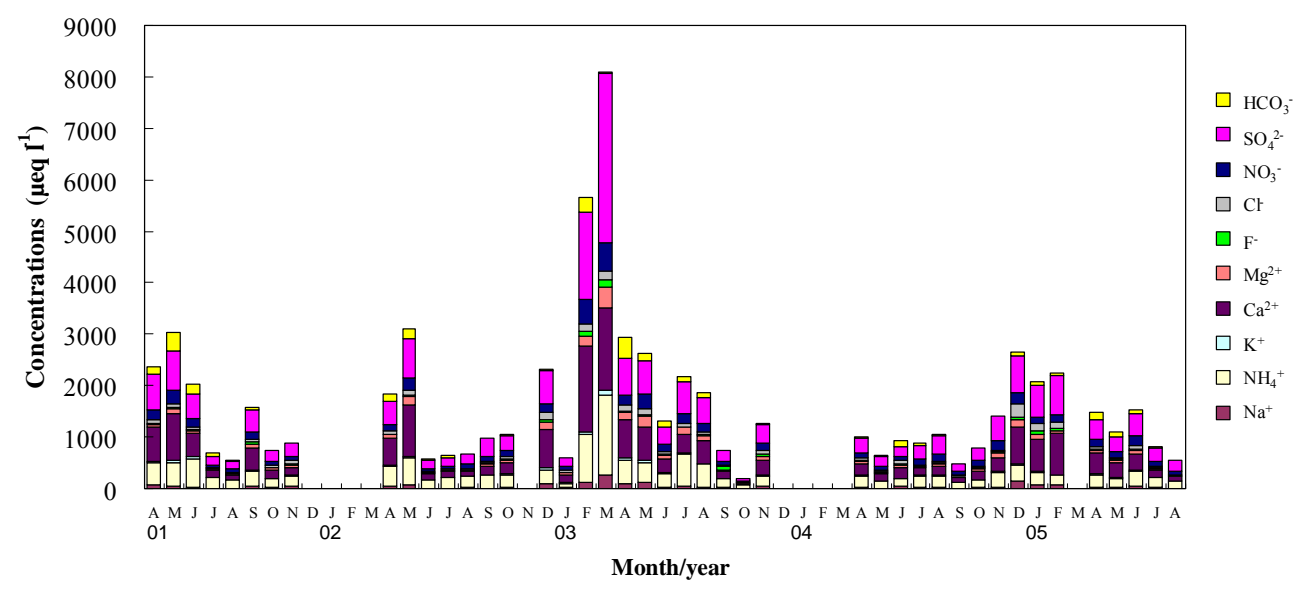

Fig. 6. Monthly variations in the VWM concentrations of ions in precipitation from April 2001 to August 2005.

seasonal distribution of precipitation volume in 2003 differed enormously from those in the other years. The precipitation volumes in the winter, spring, and fall in 2003 increased by $50-160 \%$ whereas the summer rain volume substantially declined. The low annual volume and abnormal seasonal distribution of the precipitations likely played a role in the unusual monthly variations in precipitation chemistry in 2003. High concentrations of precipitation ions in Beijing in the year 2003 were also reported by $\mathrm{Hu}$ et al. (2005).

Based on linear regression throughout the study period, $\mathrm{SO}_{4}^{2-}$ maintained a steady concentration level, whereas $\mathrm{NO}_{3}^{-}$ exhibited an increasing trend and $\mathrm{NH}_{4}^{+}$and $\mathrm{Ca}^{2+}$ a decreasing trend in their concentrations. In comparison with the study conducted in Beijing during 1995-1998 (Table 1), the VWM concentrations of most ions in this study decreased by $13 \%\left(\mathrm{SO}_{4}^{2-}\right)$ to $64 \%\left(\mathrm{Cl}^{-}\right)$, whereas those of $\mathrm{NO}_{3}^{-}$and $\mathrm{NH}_{4}^{+}$ increased by $94 \%$ and $75 \%$. This is in agreement with the finding by Okuda et al. (2011) that opposite to the decreasing trend in other water-soluble ions of particulate matter in Beijing was an evident increasing trend in nitrogen-containing species in recent years. However, the decrease in $\mathrm{SO}_{4}^{2-}$ level did not scale to the $58 \%$ decrease in the annual mean $\mathrm{SO}_{2}$ concentration from 1998 to $2005\left(50 \mu \mathrm{g} \mathrm{m}^{-3}\right.$ in 2005). What seems more surprising is that the $\mathrm{NO}_{3}^{-}$growth was opposite to the $5 \%$ reduction in the annual mean $\mathrm{NO}_{2}$ concentration from 1998 to 2005 (66 $\mu \mathrm{g} \mathrm{m}^{-3}$ in 2005).

These counterintuitive long-term changes in $\mathrm{SO}_{4}^{2-}$ and $\mathrm{NO}_{3}^{-}$concentrations in the precipitations as compared to their precursors were likely due to the increased regional transport and reinforced conversion of precursors to acid compounds and/or secondary particles. While huge progress has been made in eliminating small coal-fired boilers in urban Beijing (Okuda et al., 2008), it is still popular to burn coal at the household level in sprawling brick-home suburbs and surrounding areas, and to burn agricultural field residue after harvest (Yang et al., 2010). Opposite to the more or less decline of ambient $\mathrm{SO}_{2}$ and $\mathrm{NO}_{2}$ levels in Beijing from 1998 to 2005 , the national $\mathrm{SO}_{2}$ emissions (2549.3 Mt in 2005) increased by $22 \%$ in the span (EQA, 1998, 2005). The national $\mathrm{NO}_{\mathrm{x}}$ emission had undergone even much larger growth during the period (18.6 Mt in 2004 vs. $11.7 \mathrm{Mt}$ in 1998) according to Zhang et al. (2007). Therefore, it was anticipated that there were growing transport of the acid compounds (i.e. $\mathrm{SO}_{4}^{2-}$ and $\mathrm{NO}_{3}^{-}$) formed from gaseous precursors to Beijing, especially from the vast eastern region upwind to the south in rainy months. This region is densely populated, with several large urban centers such as Tianjin Municipality (13 million), Shijiazhuang (10 million), Jinan (6.8 million), and Qingdao (8.7 million), which are typical industrial, coal-burning cities within several hundred kilometers of Beijing (Fig. 1). In these areas, emission controls on stationary sources and vehicles are not as stringent as in Beijing, and emissions are high (Streets et al., 2007). The $\mathrm{SO}_{2}$ and $\mathrm{NO}_{2}$ emission per land area in the eastern region of China was 3.3 and 4.4 times of their corresponding national averages (Yang et al., 2011b). In addition, the sulfate reduction frees up ammonia to react with nitric acid to form more nitrate (Seinfeld and Pandis, 2006), which was at least partly responsible for the nearly doubled $\mathrm{NO}_{3}^{-}$concentrations in the precipitations. More careful study is needed to quantitatively determine all the contributions.

\subsection{Trends in the acidifying and neutralizing potential, and the form of acidity}

Tsurata (1989) defined $\left[\mathrm{NO}_{3}^{-}+\mathrm{nss}-\mathrm{SO}_{4}^{2-}\right]$ as acidifying potential (AP) and $\left[\mathrm{NH}_{4}^{+}+\mathrm{nss}^{\left.-\mathrm{Ca}^{2+}\right]}\right.$ as neutralizing potential (NP). Time series of the ratios of NP to AP (NP/AP) were plotted in Fig. 7a. The high NP/AP (1.2 on average) indicates that wet deposition in Beijing had strong neutralization potential to offset the acidity caused by high loadings of sulfuric and nitric acids. However, the NP/NA ratio exhibited a significant decreasing trend with the regression intercept down from 1.5 to less than 1.0 over the study period. The average ratio was significantly lower than that (1.45) determined 

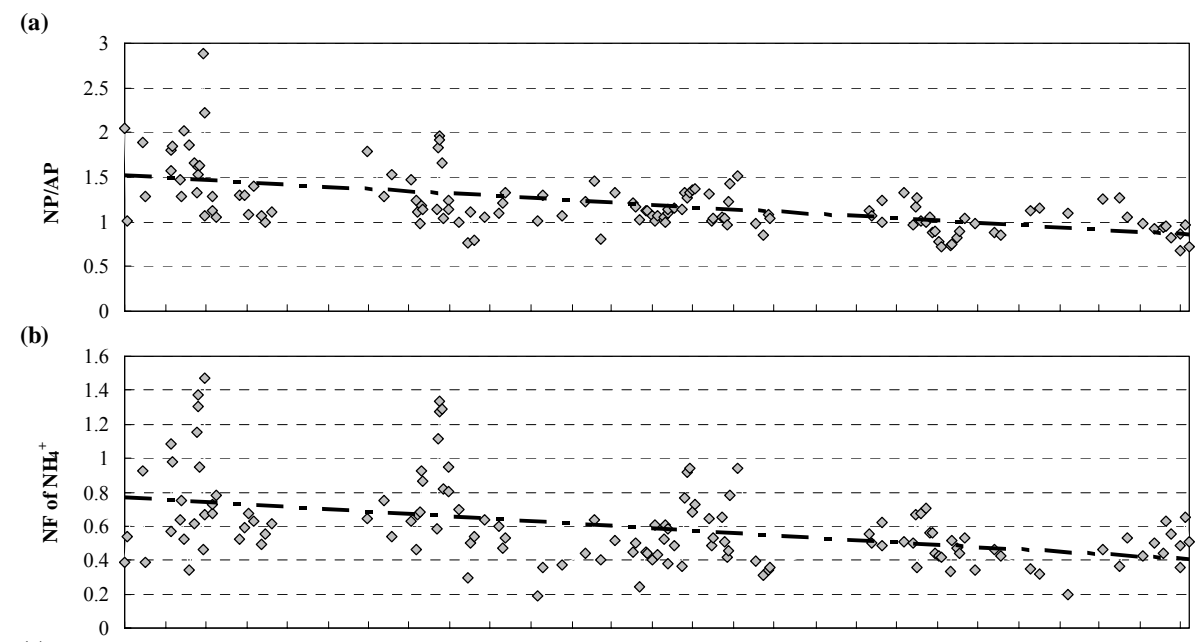

(c)

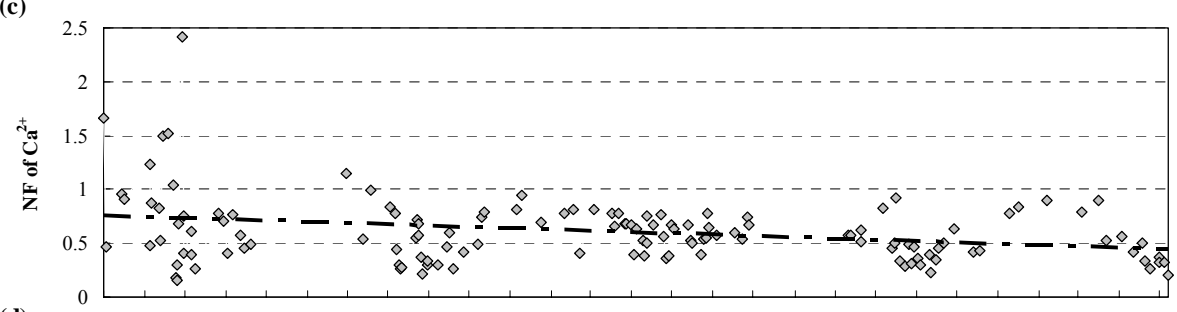

(d)

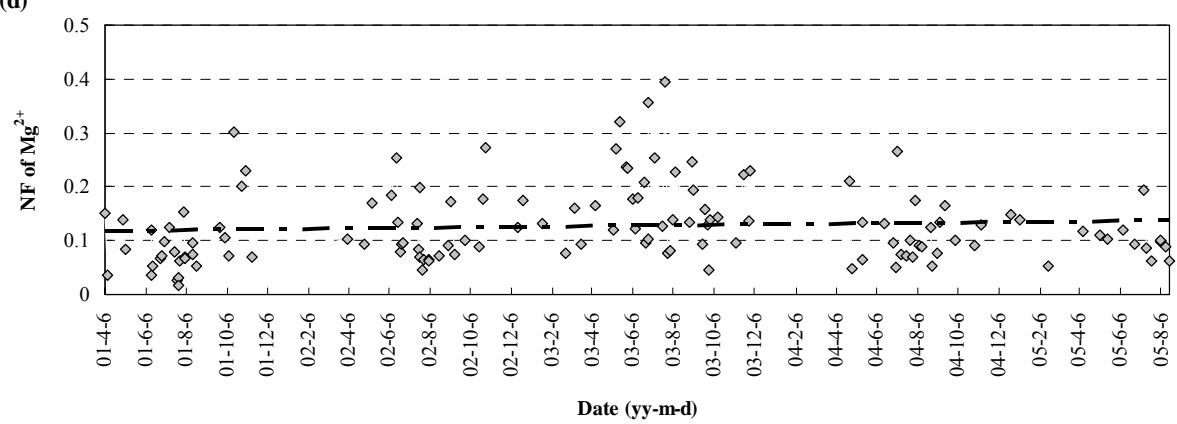

Fig. 7. Time series of (a) the equivalent mass ratios of NP (neutralizing potential) to AP (acidifying potential), (b) the NF (neutralization factor) of $\mathrm{NH}_{4}^{+}$, (c) the $\mathrm{NF}$ of $\mathrm{Ca}^{2+}$ and (d) the $\mathrm{NF}$ of $\mathrm{Mg}^{2+}$.

in Beijing during 1995-1998 (Feng et al., 2001), suggesting again the decreasing neutralization trend was likely a longterm trend for Beijing precipitations.

Time series of the neutralization factors (NFs) of $\mathrm{NH}_{4}^{+}$, $\mathrm{Ca}^{2+}$, and $\mathrm{Mg}^{2+}$ based on the following empirical relation are plotted in Fig. 7b-d:

$(\mathrm{NF})_{X}=[\mathrm{X}] /\left[\mathrm{NO}_{3}^{-}+\mathrm{nss}-\mathrm{SO}_{4}^{2-}\right]$

where $X=\mathrm{NH}_{4}^{+}$, nss-Ca ${ }^{2+}$, and nss- $\mathrm{Mg}^{2+}$.

The NFs of $\mathrm{NH}_{4}^{+}, \mathrm{Ca}^{2+}$ and $\mathrm{Mg}^{2+}$ varied largely from $0.19-1.5,0.15-2.4$ and $0.02-0.40$ with their average values of $0.60 \pm 0.25,0.60 \pm 0.31$ and $0.13 \pm 0.17$, respectively, reflecting the dominant neutralization of $\mathrm{NH}_{4}^{+}$and $\mathrm{Ca}^{2+}$ over $\mathrm{Mg}^{2+}$. There were evident decline trends in the $\mathrm{NFs}$ of $\mathrm{NH}_{4}^{+}$ and $\mathrm{Ca}^{2+}$, whereas that of $\mathrm{Mg}^{2+}$ underwent a clear growth over the study period. Although of small neutralization fac- tor, the trend in $\mathrm{NF}$ of $\mathrm{Mg}^{2+}$ likely pointed to a growing contribution from construction activities since magnesium has been identified as an indicator element of cement dust (Yang et al., 2005). Along with other measures to control stationary and mobile source emissions in Beijing, construction and demolition areas have been required to control fugitive dust. However, ambient $\mathrm{PM}_{10}$ were still at high levels with the annual mean concentrations ranging $141-165 \mu \mathrm{g} \mathrm{m}^{-3}$ over the study period (www.bjepb.gov.cn). This was attributed partially to the unprecedented high levels of construction activities due to rapid urbanization. For example, Yang et al. (2004) reported that there were more than 1200 construction and demolition sites in urban Beijing in June 2001, covering a total area of about $32 \mathrm{~km}^{2}$.

Nitrate-to-sulfate equivalent ratio (i.e. $\left[\mathrm{NO}_{3}^{-}\right] /\left[\mathrm{SO}_{4}^{2-}\right]$ ) can be used to infer the form of acidity in the precipitation 


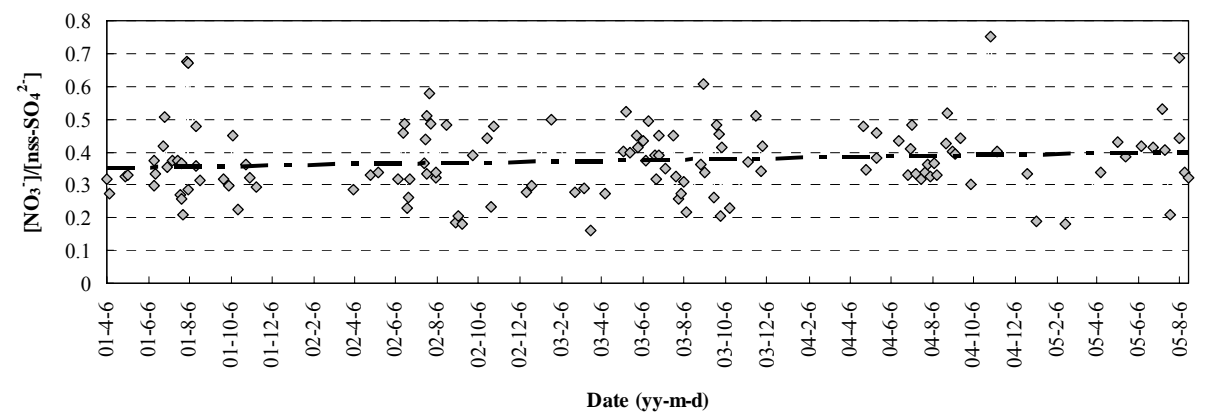

Fig. 8. Time series of the equivalent mass ratios of $\mathrm{NO}_{3}^{-}$to $\mathrm{SO}_{4}^{2-}$.

(Tuncer et al., 2001). As illustrated in Fig. 8, a clear increasing trend in $\left[\mathrm{NO}_{3}^{-}\right] /\left[\mathrm{nss}-\mathrm{SO}_{4}^{2-}\right]$ with a $\sim 0.05$ increment to 0.4 for its regression intercept was found over the study period. The ratios varied from 0.16 to 0.74 with an average of at $0.37 \pm 0.11$. This average ratio was more than twice that $(0.15)$ calculated from the data measured in Beijing during 1995-1998 (Feng et al., 2001), indicating that the relatively reinforced contribution of nitric acid to precipitation acidity was also a long-term trend. This is in agreement with the trend in $\left[\mathrm{NO}_{3}^{-}\right] /\left[\mathrm{SO}_{4}^{2-}\right]$ of fine particles in Beijing (Yang et al., 2011b). This $\left[\mathrm{NO}_{3}^{-}\right] /\left[\mathrm{nss}-\mathrm{SO}_{4}^{2-}\right]$ value was twice as much as that during the same period in Chongqing $(0.18 \pm 0.35)$ - a typical acid rain area with abundant high-sulfur coal consumption in Southwest China (marked in Fig. 1) - but was significantly lower than that in Tokyo Metropolis (Okuda et al., 2005) and a metropolis (Newark) in the US East Coast (Song and Gao, 2009). These comparisons showed that the precipitation acidity in Beijing was still dominantly from excessive emissions of sulfur (i.e. sulfur type).

\section{Conclusions}

Event-based precipitation samples were collected from March 2001 to August 2005 at an urban location in Beijing to investigate the temporal variations in the precipitation chemistry and to explore the possible mechanisms influencing the variations. The $\mathrm{pH}$ of single rain sample varied from 4.2 to 7.5 with an arithmetic mean of 6.3 and VWM of 6.0 for the total 131 rain events. About $16 \%$ of rain events were acidic and the yearly wet deposition acidity was dominated by the summertime precipitations, as they shared about two-thirds of the annual volume and usually had low $\mathrm{pH}$ values. The precipitation acidity was on the growth track and the process was likely being accelerated. $\mathrm{SO}_{4}^{2-}$ was the most abundant ion with the VWM concentration of as high as $314 \mu \mathrm{eq} \mathrm{l}^{-1}$. $84 \%$ of anionic mass was from $\mathrm{SO}_{4}^{2-}$ and $\mathrm{NO}_{3}^{-}$, followed in decreasing order by $\mathrm{HCO}_{3}^{-}, \mathrm{Cl}^{-}$and $\mathrm{F}^{-}$. The precipitation acidity was predominantly neutralized by $\mathrm{NH}_{4}^{+}$and $\mathrm{Ca}^{2+}$ with their percentage contribution of $83 \%$ to total cationic mass.

The concentrations of both crustal-related and anthropogenic ions in the precipitation were much higher during the dry months than during the rainy months. The high NP/AP ratio (1.2 on average) indicated that the precipitations in Beijing had strong neutralizing potential to offset the acidity caused by high loadings of sulfuric and nitric acids. However, the NP/AP ratio exhibited a significant decreasing trend over the study period and particularly compared to that (1.45) determined pre-1998. This was mainly resulted from reduced input of $\mathrm{NH}_{4}^{+}$and $\mathrm{Ca}^{2+}$ and increased input of $\mathrm{NO}_{3}^{-}$. In comparison to more or less decline of $\mathrm{SO}_{2}$ and $\mathrm{NO}_{2}$ in the ambient air of Beijing, the mean concentrations of $\mathrm{SO}_{4}^{2-}$ and $\mathrm{NO}_{3}^{-}$in the precipitations showed much less decline and unexpected growth over the past decade, respectively. The growing contribution of $\mathrm{NO}_{3}^{-}$to the precipitation acidity was also a long-term trend, although the acidity was still dominantly from sulfur oxide emissions but not nitrogen oxide.

Acknowledgements. The authors are grateful to Xuechun Yu, Yu Lei, Yingtao Jia, Qing Zhao, Tamami Iwase, Hideko Ueda and Yusuke Suda for their contributions to the filed and laboratory work, and Li Bai, Qingqing Wang and Lianfang Wei for their contributions to the manuscript preparation. This study was funded by Tsinghua-Keio 3E Project, the National Basic Research Program of China (2010CB951803), and National Natural Science Foundation (21190054, 41075093). Zongbo Shi is funded by NERC fellowship (NE/I021616/1).

Edited by: X. Tie

\section{References}

Aiuppa, A., Bonfanti, P., and Alessandro, W. D.: Rainwater chemistry at Mt. Etna (Italy), natural and anthropogenic sources of major ions, J. Atmos. Chem., 46, 89-102, 2003.

Ayers, G. P.: Some practical aspects of acid deposition measurement, The Third Expert Meeting on Acid Deposition Monitoring Network in East Asia, Niigata Prefecture, Japan, pp. 1-20, 14-16 November 1995. 
Barnard, W. R. and Nordstrom, D. K.: Fluoride in precipitationII: implications for the geochemical cycling of fluoride, Atmos. Environ., 16, 105-111, 1982.

Beijing Municipal Bureau of Statistics: Beijing statistical Yearbook, online available at: http://www.bjstats.gov.cn/nj/main/ 2011-tjnj/index.htm, 2011, last access: January 2012 (in Chinese).

Ding, G., Xu, X., Fang, X., Jin, Shu., Xu, X., Tang, J., Liu, Q., Wang, S., and Wang, W.: The status and trend of acidic rain in China, Chinese Sci. Bulletin, 42, 169-173, 1997 (in Chinese).

EQA: Announcement of Environmental Quality in China (in Chinese), online available at http://www.sepa.gov.cn/plan/zkgb, 1998 and 2005, last access: August 2011.

Feng, Z., Huang, Y., Feng, Y., Ogura, N., and Zhang, F.: Chemical composition of precipitation in Beijing area, Northern China, Water, Air, and Soil Pollut., 125, 345-356, 2001.

Feng, Y. W., Ogura, N., Feng, Z. W., Zhang, F. Z., and Shimizu, H.: The concentrations and sources of fluoride in atmospheric depositions in Beijing, China, Water, Air, and Soil Pollut., 145, 95-107, 2003.

Fujita, S., Takahashi, A., Weng, J., Huang L. F., Kim H. K., Li C. K., Huang F. T. C., and Jeng F. T.: Precipitation chemistry in East Asian, Atmos. Environ., 34, 525-537, 2000.

Ge, B. Z., Wang, Z. F., Xu, X. B., Tang, J., He, Y. J., Uno, I., and Ohara, T.: Impact of the East Asian summer monsoon on longterm variations in the acidity of summer precipitation in Central China, Atmos. Chem. Phys., 11, 1671-1684, doi:10.5194/acp11-1671-2011, 2011.

Grodzińska-Jurczak, M. and Godzik, B.: Air pollution and atmospheric precipitation chemistry in Poland - a review, Environ. Rev., 7, 69-79, 1999.

Guinot B., Cachier, H., Sciare, J., Yu, T., Wang, X., and Yu, J.: Beijing aerosol: Atmospheric interactions and new trends, J. Geophys. Res., 112, D14314, doi:10.1029/2006JD008195, 2007.

He, K., Yang, F., Ma, Y., Zhang, Q., Yao, X., Chan, C. K., Cadle, S., Chan, T., and Mulawa, P.: The characteristics of $\mathrm{PM}_{2.5}$ in Beijing, China, Atmos. Environ., 35, 4959-4970, 2001.

He, K., Yang, F., Duan, F., and Ma, Y. (Eds.): Atmospheric particulate matter and regional complex pollution, China Science Press, Beijing, China, 2011 (in Chinese).

Hontoria, C., Saa, A., Almorox, J., Cuadra, L., Sánchez, A., and Gascó, J. M.: The chemical composition of precipitation in Madrid, Water, Air, Soil Pollut., 146, 35-54, 2003.

$\mathrm{Hu}, \mathrm{M}$., Zhang, J., and Wu, Z.: Chemical compositions of precipitation and scavenging of particles in Beijing, Sci. in China-Chem., 48, 265-272, 2005.

Huang, D. Y., Xu, Y. G., Peng P. A., Zhang, H. H., and Lan. J. B.: Chemical composition and seasonal variation of acid deposition in Guangzhou, South China: Comparison with precipitation in other major Chinese cities, Environ. Pollut., 157, 35-41, 2009.

Huang, K., Zhuang, G. S., Xu, C., Wang, Y., and Tang, A. H.: The chemistry of the severe acidic precipitation in Shanghai, China, Atmos. Res., 89, 149-160, 2008.

Larssen, T., Lydersen, E., Tang, D. G., He, Y., Gao, J. X., Liu, H. Y., Duan, L., Seip, H. M., Vogt, R. D., Mulder, J., Shao, M., Wang, Y. H., Shang, H., Zhang, X. S., Solberg, S., Aas, W., Okland, T., Eilertsen, O., Angell, V., Liu, Q. R., Zhao, D. W., Xiang, R. J., Xiao, J. S., and Luo, J. H.: Acid rain in China, Environ. Sci. Technol., 40, 418-425, 2006.
Moller, D.: The $\mathrm{Na} / \mathrm{Cl}$ ration in rainwater and the seasalt chloride cycle, Tellus B, 423, 254-262, 1990.

Neal, C.: Fluoride variations in Welsh stream and soil water, Sci. Total Environ., 80, 213-223, 1989.

Okuda, T., Iwase, T., Ueda, H., Suda, Y., Tanaka, S., Dokiya, Y., Fushimi, K., and Hosoe, M.: Long-term trend of chemical constituents in precipitation in Tokyo metropolitan area, Japan, from 1990 to 2002, Sci. Total Environ., 339, 127-141, 2005.

Okuda, T., Katsuno, M., Naoi, D., Nakao, S., Tanaka, S., He, K., Ma, Y., Lei, Y., and Jia, Y.: Trends in hazardous trace metal concentrations in aerosols collected in Beijing, China from 2001 to 2006, Chemosphere, 72, 917-924, 2008.

Okuda, T., Matsuura, S., Yamaguchi, D., Umemura, T., Hanada, E., Orihara, H., Tanaka, S., He, K., Ma, Y., Cheng, Y., and Liang, L.: The impact of the pollution control measures for the 2008 Beijing Olympic Games on the chemical composition of aerosols, Atmos. Environ, 45, 2789-2794, 2011.

Özsoy, T., Türker, P., and Örnektekin, S.: Precipitation chemistry as an indicator of urban air quality in Mersin, North-Eastern Mediterranean Region, Water, Air, Soil Pollut., 189, 69-83, 2008.

Seinfeld, J. H. and Pandis, S. N.: Atmospheric chemistry and physics: From air pollution to climate change, John Wiley \& Sons, New York, 2006.

Song, F. and Gao, Y.: Chemical characteristic of precipitation at metropolitan Newark in the US East Coast, Atmos. Environ., 43, 4903-4913, 2009.

Streets, D. G., Fu, J. S., Jang, C. J., Hao, J., He, K., Tang, X., Zhang, Y., Wang, Z., Zhang, Q., Wang, L., Wang, B., and Yu, C.: Air quality during the 2008 Beijing Olympic Games, Atmos. Environ., 41, 480-492, 2007.

Tang, A., Zhuang, G., Wang, Y., Sun, Y., Yuan, H., and Sun, Y.: The chemistry of precipitation and its relation to aerosol in Beijing, Atmos. Environ., 39, 3397-3406, 2005.

Tang, J., Xue, H., Yu, X., Cheng, H., Xu, X., Zhang, X., and Ji, J.: The preliminary study on chemical characteristics of precipitation at Mt. Waliguan, ACTA Sci. Circumstantiate, 20, 420-425, 2000 (in Chinese).

Tang, J., Xu, X., Ba, J., and Wang, S.: Trends of the precipitation acidity over China during 1992-2006, Chinese. Sci. Bul., 5, 1800-1807, 2010.

Tsurata, H.: Acid precipitation in Asia, Kagaku, 59, 305-315, 1989.

Tuncer, B., Bayar, B., Yesilyurt, C., and Tuncela, G.: Ionic composition of precipitation at the Central Anatolia (Turkey), Atmos. Environ., 35, 5989-6002, 2001.

Wang, W. and Wang, T.: On the origin and the trend of acid precipitation in China, Water, Air, and Soil Pollut., 85, 2295-2300, 1995.

Wang, W. X. and Xu, P. J.: Research progress in precipitation chemistry in China, Prog. Chem., 21, 266-281, 2009 (in Chinese).

Wang, W. and Zhang, W.: On the precipitation acidity in Beijing, Chinese Environ. Res., 10, 6-9, 1997 (in Chinese).

Wang, Y., Wai, K. M., Gao, J., Liu, X., Wang, T., and Wang, W.: The impacts of anthropogenic emissions on the precipitation chemistry at an elevated site in North-eastern China, Atmos. Environ., 42, 2959-2970, 2008.

Xie, Z. Q., Du, Y., Zeng, Y., Li, Y. C., Yan, M. L., and Jiao, S. M.: Effects of precipitation variation on severe acid rain in southern China, J. Geogr. Sci., 19, 489-501, 2009. 
Xu, Z. F. and Han, G. L.: Chemical and strontium isotope characterization of rainwater in Beijing, China, Atmos. Environ., 43, 1954-1961, 2009.

Yang, F., Brook, J., He, K., Duan, F., and Ma, Y.: Temporal variability in fine carbonaceous aerosol over two years in two megacities: Beijing and Toronto, Adv. Atmos. Sci., 27, 705-714, doi:10.1007/s00376-009-9103-6, 2010.

Yang, F. M., He, K. B., Ma, Y. L., Cadle, S. H., Chan, T., and Mulawa, P. A.: Characteristics of Mineral Component in Ambient $\mathrm{PM}_{2.5}$ in Beijing, Environ. Sci., 25, 26-30, 2004 (in Chinese).

Yang, F. M., Ye, B. M., He, K. B., Ma, Y. L., Cadle, S. H., Chan, T., and Mulawa, P. A.: Characterization of atmospheric mineral components of $\mathrm{PM}_{2.5}$ in Beijing and Shanghai, China, Sci. Total Environ., 343, 221-230, 2005.

Yang, F., Huang, L., Duan, F., Zhang, W., He, K., Ma, Y., Brook, J. R., Tan, J., Zhao, Q., and Cheng, Y.: Carbonaceous species in $\mathrm{PM}_{2.5}$ at a pair of rural/urban sites in Beijing, 2005-2008, Atmos. Chem. Phys., 11, 7893-7903, doi:10.5194/acp-11-78932011, 2011a.
Yang, F., Tan, J., Zhao, Q., Du, Z., He, K., Ma, Y., Duan, F., Chen, G., and Zhao, Q.: Characteristics of $\mathrm{PM}_{2.5}$ speciation in representative megacities and across China, Atmos. Chem. Phys., 11, 5207-5219, doi:10.5194/acp-11-5207-2011, 2011 b.

Zhang, F. Z., Zhang, J. Y., Zhang, H. R., Orgura, N., and Ushikubo, A.: Chemical composition of precipitation in a forest area of Chongqing, southwest of China, Water, Air, Soil Pollut., 90, 407-418, 1996.

Zhang, Q., Streets, D. G., He, K., Wang, Y., Richter, A., Burrows, J. P., Uno, I., Jang, C. J., Chen, D., Yao, Z., and Lei, Y.: $\mathrm{NO}_{\mathrm{X}}$ emission trends for China, 1995-2004: The view from the ground and the view from space, J. Geophys. Res., 112, D22306, doi:10.1029/2007JD008684, 2007.

Zhao, D. and Wang, A.: Emission of anthropogenic ammonia emission in Asia, Atmos. Environ., 28A, 689-694, 1994.

Zhao, D. W., Xiong, J. L., Xu, Y., and Chan, W. H.: Acid-Rain in Southwestern China, Atmos. Environ., 22, 349-358, 1988.

Zheng, B. S. (Ed.): A study on fluoride pollution and fluorosis cases in industry area, China Environ. Sci. Press, Beijing, China, 1996 (in Chinese). 